\title{
The High Impact of Low Tech in Social Work ${ }^{1}$
}

\begin{abstract}
Summary
Drawing on actor-network theory, this paper challenges the traditional analytical separation of the socalled social and the so-called technical. First, observational data of an interactional event between a social worker and a client is introduced. Second, the techno-social heterogeneity of the event is elucidated through an analysis based on the concept of translation. Third, the precarious and temporary natures of the techno-social hybrids are discussed through the concept of performance. Finally, the techno-social is proposed as a new object for social science.
\end{abstract}

I n September 2000 Outlines organised a conference with the title Technology in Social Practice. I would like to begin this article with a few brief comments on this title. What I find particularly interesting is the word 'in'. For the sake of the argument, I will make a wild comparison. What do we get if we put chicken into soup? Do we get "Chicken in soup"? No, of course not, after a little while and some boiling we simply get chicken soup. This is because the chicken and soup blend into each other. But apparently the 'in' in the conference title suggests that this does not happen with the technology and the social practice. Apparently they are distinct even though one is inside the other. And even though they are joined in practice, they can be re-separated if we wish to do so - for instance in an analysis.

Another interesting thing about the 'in' is the particular relation of size and importance that is suggested. The social is somehow bigger or more encompassing than the technical. Otherwise technology in social practice would make no sense. So the title suggests that the technological is played out on a stage set up by the social. We, in the social sciences, might consider this a self-evident fact given in the order of things. But if we made a trip to the nearest engineering academy we would encounter the complete opposite world-view. They would talk about the human factors in particular technologies, and by doing that they would place the social within the technical - not the other way around.

So "Technology in Social Practice" suggests non-blending and it suggests the primacy of the social. In this article, I will challenge both of these assumptions.

My theoretical point of departure will be some concepts developed by actor-network theory (ANT) - a theory that deliberately

\footnotetext{
1 An earlier version of this paper was presented on the Outline-conference Technology in Social Practice at the University of Copenhagen, September 2000.
} 
and notoriously blends the social and the technical (Latour 1987, Callon 1986, Law 1992).

My empirical point of departure will be a small piece of material from a study of social work. As the reader is probably well aware, social work is a very low-tech field. But none the less, I will show that the practice of social work is a blend of the so-called social and the so-called technical.

A techno-social chicken soup, if you like.

\section{An observation of social work}

$\mathrm{L}$ ast year, I spent quite a lot of time observing and interviewing social workers in a social centre in Copenhagen. On one particular day, I was making observations of the work at the counter. The counter is in the reception area where clients are serviced, when they come in from the street. Participant observation is the term that social psychologists might casually use for this type of endeavour. But participation would have been a nightmare for me. I have very little knowledge of the daily business of social work, so I would have made a fool of my self in seconds if I had to take part in the work at the counter. To protect me from participation the caseworkers had created a cover: They assigned me a desk and a pile of case files to hide behind. If a long line of clients was building up, and the clients started wondering why $I$ didn't do any work, then I could easily duck behind my pile of cases and pretend that I was busy. So there I was, sitting at a desk behind my cover, overhearing conversations and frantically writing field notes.

After a little while, the following event occurred (extracted from field notes):

\begin{tabular}{|c|c|c|}
\hline 1 & & $\begin{array}{l}\text { [A client walks up to the counter. The caseworker gets up from her } \\
\text { chair and approaches the counter] }\end{array}$ \\
\hline 2 & Client : & I have applied for a licensed sewer worker education. \\
\hline 3 & Caseworker: & What is your social security number? \\
\hline 4 & Client: & $\begin{array}{l}\text { You don't have to find my case. I'm running from one office to the } \\
\text { next. Why don't you send me a letter about what is happening? }\end{array}$ \\
\hline 5 & Caseworker: & You want to get an answer! \\
\hline 6 & Client: & Yes. \\
\hline 7 & Caseworker: & I'll just find your case and see if something has happened. \\
\hline 8 & & [The client agrees and states his social security number. \\
\hline 9 & & $\begin{array}{l}\text { The caseworker walks to a file cabinet, finds his case and reads } \\
\text { for a little while. She returns and informs him that nothing has } \\
\text { happened. }\end{array}$ \\
\hline 10 & & $\begin{array}{l}\text { The caseworker offers the client an appointment with the case- } \\
\text { worker in charge of the case. }\end{array}$ \\
\hline 11 & & The client agrees. \\
\hline 12 & & $\begin{array}{l}\text { She finds the meeting schedule and they set a date and a time. } \\
\text { The client leaves.] }\end{array}$ \\
\hline
\end{tabular}


Outlines-2001-1. qxd 19-06-01 13:31 Side 83

I believe most people would agree that this is a rather trivial event. It is highly unlikely that the client would go home and write complaint. The caseworkers wouldn't think much about the encounter and it wouldn't be a topic in their lunch break conversations. Even the most imaginative tabloid journalist couldn't make a story out of it. This is simply the kind of mundane event that everyday life in the social centre is full off.

So what should we make of it? And what if anything does it have to do with technology?

To begin, I would like to make three straightforward observations about the event:

1. It works. The event is somehow functional. Whatever technological or social there is 'in' this event, it plays together in a rather seamless way.

2. Identity. Something happens to the identity of the client. He isn't quite the same in the end, as he is in the beginning.

3. Judo. There is some strange judo-trick going on. The angry and forceful complaint of the client is somehow deflected and turned against him.

\section{Translation}

$\mathrm{T}$ The first analytical tool that I will apply to this event is the concept of translation. I will use it in the specific sense that was developed by ANT in the 1980's (e.g. Callon, 1986). Following the lines of French semiotics ANT takes actors ${ }^{2}$ or entities to be relational. Entities take their form and acquire their attributes as a result of their relations with other entities (Law, 1999). Translation is a broad term covering the processes by which two entities become related in such a way that one entity replaces

2 ANT employs a semiotic definition of an 'actor'. An actor is anything that acts or receives activity from others. So the scope of actors is extended far beyond individual humans. or speaks in the name of the other. By definition, a translation move changes the attributes of the two entities because it changes (some of) the relations that constitute them. Furthermore a translation redistributes power in the actor-network; One entity is made less powerful in its role as an ally, while another entity is rendered more powerful.

The perhaps strangely neutral language of entities and translations suggests an important difference between ANT and the vast majority of social science. ANT is a move away from the types of analyses that take the world to be populated with things that have certain essences in and of themselves; technical objects, natural objects, social objects or psychological objects. On the contrary, ANT claims that these apparently essential differences are results of continual and ongoing negotiation processes in the world.

So in order to study practice we do not need these ontologies, we simply need to follow how entities become associated or disassociated. And how some entities substitute others and come to speak in their name literally or metaphorically.

If we apply this mode of analysis to the empirical case, we can describe a chain of translations. As a starting point we can pick the arrival of the client with a complaint, and at the end point we can pick the exit of the client with an appointment. Between these two points, we can pinpoint a series of translations:

1. The complaint ("why don't you send me a letter!") is translated into a wish ("you want to get an answer!').

2. The wish is translated into the stating of the social security number.

3 . The utterance of the social security number is translated into the retrieval of the case file.

4. The case file is read and compared to the wish. This comparison translates into the fact that nothing has happened. 
84

5. The fact that nothing has happened is translated to a wish for meeting.

6 . The wish is related to the meeting schedule and is then translated to an appointment.

In this series of translations a whole number of different entities are at play. A client and a caseworker, wishes and complaints, social security numbers and meetings, case files and schedules. If the goal was simply to unfreeze the rigid boundaries between the technical and the social, then it is quite obvious that the notion of translation is already doing the work that it was supposed to.

Now, the fact that one thing changes into another that changes into yet another is of course only moderately interesting. What is more interesting is the pattern of translations. What aspects of the world are produced and reproduced through this event?

To analyse these matters, actor-networktheorists have invented a number of terms to describe how certain entities manage to persuade others to undergo translations.

One term is called interessement. This is when one entity tells another: this is what you really want to be. Your are complaining that we don't send you a letter, you define yourself as an accuser of the system. But we - the system, the social worker, and the way we normally go about things - suggest that you want an answer. That is what you really want to be.

If interessement is successful, then the translation itself can take place. One entity is substituted by another. The complaint is replaced by the wish for an answer. This wish is now the centre of attention, whereas the complaint slips in the background.

Finally, by participating in the translation, a particular entity lets itself enrol in a network. When the client replaces a complaint with a wish, he is enrolled into a network that ascribes him a particular role. One part of this is to state his social security number, an action he refused just a little while ago. A mandatory, standardised action such as stating the social security number is called an obligatory passage point in ANT. Entities that are enrolled in the network are persuaded to move through these points, and thus contributing to the stiffening and routinisation of the network. It almost goes without saying that the entities that successfully define and control obligatory passage points become indispensable and grow in strength. To take one very obvious example: most of us are contributing to the strength of Bill Gates because we are persuaded that Microsoft products are obligatory passage points. And of course persuaded should be taken in the broadest possible sense of the word. Not all judo-tricks are manual.

So the analytical scheme is this: Interessement, translation, enrolment. And one possible consequence is the establishment of a certain geography of obligatory passage points.

I will use this scheme on one more instance. At a certain moment it is realised that nothing has happened in the case. So the wish for an answer is blocked. Will the client get the education he applied for? No answer can be given. At this point, the caseworker makes another attempt at redefining the interest of the client. She suggests that he wants a meeting with the caseworker in charge of the case. The client seems to accept this interessement-move. Then the caseworker finds the meeting schedule and makes a translation move. The wish for a meeting is translated into the obligatory passage point of accepting an appointment with another caseworker at another time. The client also accepts this move. So now he lets himself enrol in a network where he is an element in the scheduling of work in the social centre. 
I have sketched two translations: from a complaint to the wish for an answer, and from the wish for an answer to the wish for a meeting. These two translations can be depicted as a disciplinary process. Giving the analysis a Foucaultian twist we could say that critique of 'the system' is turned into an individual problem. Resistance towards stating the social security number is turned into compliance. Impatience with the system is turned into waiting for an appointment. And finally a certain distribution of mobility is reenacted; the client must physically move to see the social workers, whereas the social workers will stay at the centre.

All this is achieved not by the social worker herself by through the intricate choreography of relations between her, the client, the social security number, the case files, the meeting schedule and numerous other elements. In this process, relations change through translations. But the actors of the actor-network are changed or re-formed as well. The part of the network, which we might call 'the bureaucracy', is solidified by once more being successful. The part of the network, which we might call 'the client', is now partially re-defined by its new connections to obligatory passage points such as a social security number and an appointment.

\section{Performance}

$\mathrm{B}$ ut if entities are what they are because of their relations, then it also follows that entities are performed or enacted into being, and that they are somehow temporary and precarious. Whatever the efficiency of the judo-trick-like translations the outcome is not a client with a coherent, stable essence to be held inside forever after.

In recent years authors within the ANT tradition, notably John Law (1994; 2001) and Annemarie Mol (1999; 2001), have tried to develop an eye for the different, precari- ous and complexly related performances.

One attempt by John Law centred on the concept of modes of ordering. He described four different ordering projects in a particular organisation. In a Foucaultian way, he argued that certain regimes of doing things make it hard to do otherwise. But in a postFoucaultian way he emphasised that several modes of ordering co-exist. None of them ever achieve perfect order and none of them grow into an all-encompassing episteme.

A mode of ordering is a certain pattern of net-work that entails a certain form of subjectivity, a certain way to go about things, and moral tale about why this is the right way to do it.

Administration is one such mode. This is the bureaucratic mode of ordering. It strives for routinisation, formalisation, and consistency. It is about defining roles, procedures, rules and hierarchies. The ideal agent is systematic, planning and meticulous. And of course cases should be processed without regard to personal or emotional considerations.

A second and very different mode of ordering is called Enterprise. This is about opportunism, pragmatism and achievement. The ideal agent is an entrepreneur who is sensitive to the shifting opportunities and demands. And this might well include bending or breaking the rules set up by the bureaucrats. Enterprise is about seizing the day and making the most of it.

These two modes of ordering might be imputed to the event in the social centre. Towards the end of the event, the client is properly processed as an element in the meeting schedule. This seems to be the mode of ordering called Administration.

In the beginning of the event something resembling Enterprise is performed. The client comes across as a free agent, accusing the system and suggesting a quick and unorthodox fix of the problem: "why don't you 
send me a letter about what is happening"

It can be quite fascinating to try to pinpoint the modes of ordering or logics that are played out in an organisation. And quite evidently modes of ordering imply technologies of various sorts. How could Administration sustain itself without file cabinets, social security numbers and meetings schedules?

It would however be a mistake to see the modes of ordering as disconnected universes. Or to picture the client as irrevocably split into an enterprise-client and an administration-client. Over and over again Law and Mol make the point that there are intricate links between performances. The client is not splintered, but he isn't quite coherent either. He, like any other object, is performed a little differently all the time. So he is more than one, but he is also less than many.

But where in the specific case are the connections between the enterprise-client and the administration-client? Doesn't it seem like an iron curtain is pulled down at the moment that the bureaucratic wheels start to spin? Isn't the client transmogrified from a critic to a docile follower? How can there be any connection between such antagonistic projects as enterprise and administration. These questions are more than I can handle in the present text. But I can make a modest attempt to sketch some answers.

First we might notice the sequence of events. In the beginning the client complains, later he is processed. It might be that administration is somehow dependent on enterprise to take place. Thus, we might speculate that ventilating anger is necessary before calm procedures can be carried out. So administration may work best when it waits a little while before it takes over.

Second, If we look at the efforts of the caseworker, they all seem to be very much by the administrative book. There is only one proper way to find a case, only one conclusion about it, and only one proper way to book an appointment. But there are also cracks in the surface. One of them is the time of the appointment. In cases of routine check-ups, clients often have to wait for several months. In this case, the client gets an appointment within weeks. So through the discretion the social worker Enterprise enters Administration. The social worker, and a meeting schedule in the middle of a bureaucratic procedure now perform the impatience that was earlier performed by a client with an angry voice.

As a third attempt to find connections between enterprise and administration we might search the internet and find the ethical rules of social workers. One of them reads: Clients are acting individuals - not objects for treatment and help. So here we have a rule - the hallmark of bureaucratic functioning - and this rule prescribes that clients are acting individuals, something much more in line with Enterprise. This is yet another example of how the different modes of ordering are related in complex ways. The simultaneous enactment of rule following and free agency.

The conclusion is quite simply that there are no iron curtains between modes of ordering. Modes of ordering do no more than clients achieve purity, singularity and order.

To end this discussion, I will make a few remarks on these ANT- inspired analyses. Everybody seems to be studying practice these years, so this is not where ANT distinguishes itself. The uniqueness of ANT is the ruthless way in which is does away with the order of things taken for granted in mainstream social science.

In a way perhaps similar to Hutchins' analysis of distributed cognition (1996), this approach doesn't come with pre-packaged notions about human subjects being the ones who act and technologies being the ones acted upon. Notions like translation and performance make it possible to study the material 
semiotics of practice, and the strange combinations that are produced. And when the initial sorting of things into subjects, objects and tools is abandoned, our sociological imaginations are opened to new and strange creatures:

Like this one:

- A client entity flowing through a series of translations and performed in a number of media.

Or this one:

- A neutral administrative mode of ordering with client anger folded into it.

So notions of the techno-social might potentially re-define what it is that we are studying in the social sciences. Just as a little low tech such as a social security number, a file cabinet and a meeting schedule blends into and reconfigures what is going on in social work.

\section{References}

Callon, M.1986. Some Elements of a Sociology of Translation: Domestication of the Scallops and the Fishermen of Saint Brieuc Bay. In J. Law (Ed.) Power, Action and Belief: a new Sociology of Knowledge?.Sociological Review Monograph. London, Routledge and Paul Kegan. 32: 196-233.
Hutchins, E. 1995. Cognition in the Wild. Cambridge, MA; London: MIT Press.

Latour, B. 1987. Science in Action: How to follow scientists and engineers through society. Cambridge, Massachusetts: Harvard University Press

Law, J. 1994. Organizing Modernity. Oxford: Blackwell.

Law, J. 1997. Traduction/Trahison: Notes on ANT. www.comp.lancs.ac.uk/sociology/stslaw2. html, Department of Sociology, Lancaster University.

Law, J. 1999. After ANT: Topology, Naming and Complexity. In J. Law and J. Hassard (Eds.) Actor Network Theory and After. Oxford and Keele: Blackwell and the Sociological Review: 1-14.

Law, J. 2001. Aircraft Stories: Decentering the Object in Technoscience. Durham, N. Ca.: Duke University Press.

Mol, A. 1999. Ontological Politics: a Word and Some Questions. In J. Law and J. Hassard (Eds.) Actor Network and After. Oxford and Keele: Blackwell and the Sociological Review: 74-89.

Mol, A. 2001. The Body Multiple: Artherosclerosis in Practice. Durham, N.Ca. and London: Duke University Press. 